OPEN ACCESS

Edited by:

Rubina Sirri

University of Bologna, Italy

Reviewed by:

Brad Buckley,

Portland State University, USA

Carlos Rosas,

Universidad Nacional Autónoma de

México, Mexico

*Correspondence:

Anna Di Cosmo

dicosmo@unina.it

Specialty section:

This article was submitted to

Aquatic Physiology,

a section of the journal

Frontiers in Physiology

Received: 29 July 2016 Accepted: 13 September 2016

Published: 28 September 2016

Citation:

Di Cosmo A and Polese G (2016) Neuroendocrine-Immune Systems Response to Environmental Stressors in the Cephalopod Octopus vulgaris.

Front. Physiol. 7:434.

doi: 10.3389/fphys.2016.00434

\section{Neuroendocrine-Immune Systems Response to Environmental Stressors in the Cephalopod Octopus vulgaris}

\author{
Anna Di Cosmo * and Gianluca Polese \\ Department of Biology, University of Napoli Federico II, Napoli, Italy
}

Under a continuous changing environment, animals are challenged with stresses and stimuli which demanding adaptation at behavioral and physiological levels. The adaptation strategies are finely regulated by animal nervous, endocrine, and immune systems. Although it's been established by now the usage of integrative approach to the study the endocrine and nervous systems (neuroendocrine), yet our understanding of how they cooperate with the immune system remains far from complete. The possible role that immune system plays as a component of the network has only been recognized recently. Octopus vulgaris is an important member of cephalopods and is considered as a model species, with considerable information about the neuroendocrine and immune systems. In the current review, we anticipate to shed light on the complexity and cross talk among the three systems and how they cooperate in setting physiological response to stresses-stimuli in O. vulgaris as a target species and primary example.

Keywords: Octopus vulgaris, immune system, neuroendocrine system, cephalopods, environmental stressor

\section{INTRODUCTION}

In aquatic and terrestrial environments, animals are continuously challenged by stressful stimuli, and in response to which, react to show a coordinated series of physiological changes (Kassahn et al., 2009). The brain/endocrine and immune systems represent the major internal correlation systems within the organisms (Tada, 1997; Elenkov et al., 2000). Although acting independently of one another, these systems communicate in an integrated way to coordinate a set of appropriate physiological and behavioral responses. In contrast to the well-established integrative approach to the study of the endocrine and nervous systems our understanding of how these three systems cooperate remains incomplete, due to the fact that immune system, as component of this network, has only recently been recognized (Demas et al., 2010). Now it is known that a variety of extrinsic and intrinsic factors can affect the regulatory network composed by three systems and they are deeply interconnected by a bi-directional communication as shown by numerous experiments in vertebrates (Blalock, 1989). However, many literatures suggest that some of the same neuroendocrine/immune connections are conserved across vertebrates and invertebrates (Ottaviani and Franceschi, 1996; Humphries and Yoshino, 2003; Cohen and Kinney, 2007; Adamo, 2008a,b; Ottaviani et al., 2008). The neuroendocrine and immune response show a combinatorial strategy where the repetitive use of a set of signaling molecules is shared by the immune and neuroendocrine systems for different purposes and functions. Interestingly, it is now believed that this cooperation has been acquired through evolution as a consequence of some 
extreme parsimonious strategies (Demas et al., 2010). It is wellknown that invertebrates possess endocrine/neuroendocrine systems, as well as, an immune system, which in turn, releases stress hormones/neurohormones in response to stress stimuli, and when it has been discovered the presence of hormone receptors in immune cells associated to intracellular signaling pathways, it has been suggested that the effects of the stress response on immune system is adaptive (Adamo, 2008a).

In mollusks, insects, and crustaceans, stress hormones are responsible for modulating immune function via maintaining immunity function under a changing internal environment (Demas et al., 2010). This continuous cross talking at molecular, cellular, and physiological levels contributes to the enhancement of some immune functions, while suppressing others. The knowledge of this balancing is critical for understanding the adaptive function of stress hormones on immune function (Adamo, 2010, 2012). On the other hand there is a shortage of data available in literatures regarding the evolutionary origin of the synergic communication between the neuroendocrine and immune systems, except of limited reports on invertebrates (Ottaviani and Franceschi, 1996; Adamo, 2008a,b).

Cephalopods (squids, cuttlefish, octopods, and nautiluses) belong to a class of the Mollusca phylum and are exclusively marine organisms that occupies a variety of different habitats, thanks to a variety of adaptations. It is estimated that out of 1000 cephalopods species, 700 have been recorded living in all oceans of the world with the exception of the Black Sea, as well as spreading from shallow waters down to deep sea, inhabiting a wide range of ecological niches. In general, and due to cephalopods wide distribution and their ability to adapt quicker to environmental changes compare to many marine species, cephalopods play an important role in community organization and ecosystem function. According to Doubleday et al. (2016), over the past six decades, cephalopod populations showed an increasing trend in proliferation in response to changes in world's oceans. Cephalopods are prey and predators and any minor changes in their health or population composition could have unknown consequences on other populations, including those used for human consumption. Moreover, many cephalopod species are considered of economic importance for fisheries and excellent candidates for aquaculture (Jereb and Roper, 2005).

Octopus vulgaris is regarded as the "candidate" species in European aquaculture, mainly for its easy acclimatization to farming conditions, rapid growth and its good market value (Vaz-Pires et al., 2004). Recently the Directive 2010/63/EU requires appropriate care and maintenance of cephalopods for research purposes urging to develop proper knowledge and practice in terms of assessment of health and disease prevention of these animals. From now on, we will outline in this short review, the wealth of information available in cephalopods (mainly in O. vulgaris) to describe the role played by neuroendocrine and immune systems in response to stressstimuli, and try to understanding the fine threads orchestrating the response to stimuli between endocrine, nervous, and immune systems. Developing an integrated approach that combines several fields such as neuroscience, physiology, immunology, ethology, ecology, and evolution will highlight the adaptive role of the different interactions and their possible role to shape behavior and host defense.

\section{NEUROENDOCRINE RESPONSE IN CEPHALOPOD O. vulgaris}

It is a well-known fact, that the endocrine system coordinates physiological processes via secretion of chemical messengers through certain organs, and that the nervous system, the other internal correlation system, plays a key role in coordinating these processes. These internal correlation systems allow the organism to respond to numerous exogenous and endogenous stimuli (environmental and physiological).

How these two systems cooperate regulating the neuroendocrine processes?

In the classical concept of input-output relations, stimuli coming from environment, as temperature, photoperiod, food, and partner's availability, are perceived by sensory organs and specific nervous areas receive, and decode the signals, and by doing so, generating internal responses that affect endocrine glands to release chemical messengers, which in turn bind to target organs. There is no doubt that the two systems work in different way as in messengers release mechanisms and the distance between release sites and target tissues. Interestingly, the messengers mode of action is restricted to one of the following types: fast neurotransmitters, slow neurotransmitters, neuromodulators, hormones, and paracrine factors (Webster et al., 2002).

In molluscs, the taxon in which endocrine gland first appeared, the nervous system is quite complex, exhibiting a different organization among classes with neurosecretory and nerve cells in the neurohemal areas and in endocrine glands (Ketata et al., 2008). This increasing complexity of neuroendocrine system has been classified as first, second, and third order control systems depending on the number of endocrine glands and target tissues (LaFont, 2000). The number of the neurosecretory organs and messenger molecules involved defines different level of complexity. In bivalves and gastropods, neurohormones secreted by nervous ganglia and gonads stimulates sexual maturation showing first and second order control systems, respectively (Smit et al., 1988; Nagle et al., 1989; Smith et al., 1996; Pazos and Mathieu, 1999; De Lisa et al., 2013), while cephalopods show a third order neuroendocrine regulatory system comparable to vertebrates HPG axe (LaFont, 2000; Ketata et al., 2008; De Lisa et al., 2012; Di Cosmo and Polese, 2014).

In $O$. vulgaris the chemical messengers involved in the cross-talk between nervous and endocrine system in reproduction control, are classified into three main categories: neurotransmitters, neuromodulators, and hormones considering their chemical properties and mechanism of action (Di Cosmo and Polese, 2014). Several neuropeptides, neurotransmitters, and hormones has been detected in the nervous lobes and endocrine glands controlling reproduction in O. vulgaris giving rise to the model recently proposed (Di Cosmo and Polese, 2014; Polese et al., 2015). In this model the nervous lobes that control 
the olfaction, the olfactory lobes, and the olfactory organs, are at the center of a dense network of molecules that provides connection to the nervous system and the endocrine glands; then they regulate the switch on-off between energy storage and reproduction. The question to be asked here is, how this regulation occurs?

The olfactory information coming from the environment determines: feeding choices, selection of mates and habitats, competitive interactions, and energy transfer within and among ecosystems. These informations are detected by olfactory organs that are connected by olfactory nerve to olfactory lobes. The olfactory lobes are responsible for modulating the olfactory organs to be more sensitive to food odors, especially during the energy storage period (from paralarva to adult), which in turn inhibits the activity of optic gland responsible for gonad maturation switching off reproduction. On the other hand, and during the reproductive period, the olfactory lobes modulate the olfactory organs to be more sensitive to sex odors switching on reproduction. This model, which links the nervous and endocrine systems, shows how the two systems are provide a coordinate response to a variety of stimuli coming from environment to optimize the animal fitness.

\section{IMMUNE RESPONSE IN CEPHALOPOD O. vulgaris}

It's well-documented that wild and reared cephalopods are affected by a variety of pathogens, as in the form of bacteria, protozoa, and metazoan parasites (Castellanos-Martínez and Gestal, 2013). Yet, research aiming at understanding cephalopods-pathogens interaction, especially in octopus and squid, is very limited, especially when compared to understanding immune response in other commercially important marine species, making it difficult to make generalizations across species (Ford, 1992; Pascual and Guerra, 2001; Castellanos-Martínez and Gestal, 2013; Troncone et al., 2014). Similarly, knowledge concerning immune and neuroendocrine systems, and the coordination between the two systems in response to different diseases, is fully unclear. All these facts lead us to focus on studying the immune system of cephalopods, particularly $O$. vulgaris, and to investigate the relationship between the immune and neuroendocrine responses in order to analyze how they modulate reciprocally the physiological responses required to ensure organism's health.

Cephalopods are considered "advanced" invertebrates and the only class to possess, among mollusks, a close circulatory system with one systemic, and two accessory hearts. The branchial hearts are involved in the production of hemocyanin (Schipp, 1987; Wells and Smith, 1987; Beuerlein et al., 1998, 2002). Cephalopods have an innate immune system similarly to other mollusks; their immune defense is mediated by activation of cellular factors as antibacterial peptides, whereas the immune system works on the basis of "cellular factors" (Troncone et al., 2014; Castillo et al., 2015). The cephalopod hemocytes respond by phagocytosis, encapsulation, infiltration, or cytotoxic activities to infections and destroy or isolate pathogens. The white body is the hematopoietic organ of cephalopods; this pair organ has glandular appearance, and is located behind the eyes, around the optic tracts, covered by the cranium, and it is responsible of hemocytes production (Cowden, 1972). In Octopus hubbsorum as demonstrated by Pascual et al. (2006) the hemocytes repaired the injured tissue by hook catches, moving and aggregating at the injured site. More interestingly, it has been reported that the cephalopod hemocytes are able to produce oxygen and nitrogen radicals as defense response; $\mathrm{NO}$ produced by $O$. vulgaris hemocytes seems to decrease with the increase of infection by Aggregata octopiana (Rodríguez-Domínguez et al., 2006). Furthermore, the cephalopod hemocytes can be used as an indicator of the organism's health (Ellis et al., 2011), since variations in their number and morphology has been related to parasitic infections (da Silva et al., 2008).

In addition to the role played by hemocytes, molecules dissolved in the serum (opsonins, agglutinins, lysozyme) also contribute to the immune response (Ford, 1992; CastellanosMartínez and Gestal, 2013; Troncone et al., 2014; Castillo et al., 2015; Gestal and Castellanos-Martínez, 2015). In O. vulgaris and in Octopus maya, cell-free hemolymph humoral factors as lectins, are able to agglutinate oligosaccharides from pathogens (Rögener et al., 1987a,b; Alpuche et al., 2010).

Recently our group identified in O. vulgaris hemocytes crude methanolic acid extracts, a novel antibacterial activity, the first antimicrobial activity against the most clinically isolated human pathogens. A very low concentration of this extract was able to completely inhibit bacterial growth (Troncone et al., 2014). However, we characterized the hemocyte populations based on their morphological, cytofluorometric and functional properties developing a primary hemocytes culture on a novel culture medium. In this study we identified three hemocytes population by cytofluorometric analysis, R1, R2, R3 corresponding to a gradient of a differentiation stages supporting the theory that one blast type, hemoblast-like gives origin to hyalinocytes that further mature in granulocytes. Interestingly the granulocytes, which are fully mature hemocytes, corresponding to R3 population, represent the only cell type able to proliferate. However, granulocytes are very avid phagocytes, in respect to hyalinocytes contributing actively to defense response unlike hemoblast-like cells that lack the phagocitotic activity and the intracellular enzyme system associated with immunity response (Troncone et al., 2014).

The recent advances of omics era, has had its effects on the type of data generating from O. vulgaris; it provided interesting molecular bases for $O$. vulgaris immune system through transcriptomic, genomic and proteomic approaches (Castellanos-Martínez et al., 2014a,b; Albertin et al., 2015; Gestal and Castellanos-Martínez, 2015; and ongoing project of Moroz et al. $\left.{ }^{1}\right)$. A wide and different range of genes and molecules has been identified that is believed to be involved in the cephalopod immune defense with similarities to vertebrates' immune response.

Recent transcriptome analysis in O. vulgaris hemocytes indicated that about $3 \%$ of the predicted proteins, were

$\overline{{ }^{1} \text { http://neurobase.rc.ufl.edu/cephalopods. }}$ 
actually immune function-related, as well as putative members of the complement, the Toll-like receptors (TLRSs) that were found to be highly conserved across evolution and responsible for a variety of responses to bacterial, viral, fungal infections, self-derived products, and bactericidal permeabilityincreasing protein (Rauta et al., 2013). Moreover, the peroxisome proliferator-activated receptors (PPARS), an anti-inflammatory factor able to interact with transcription factors involved in inflammation also has been identified (Gestal and CastellanosMartínez, 2015). The recent findings of the specific transcripts sharing high similarity to Jaw1, a specific protein present in the lynphocytes B and T strongly suggest that similar molecules and mechanisms are conserved in phylogenetically distant animals.

Interestingly, differential analysis using high-throughput sequencing, to study coccidiosis infected $O$. vulgaris individuals, caused by parasite A. octopiana, resulted in identification of 312 genes that were differentially expressed (Gestal et al., 2007). Functional studies showed that the expression of TLR was up-regulated in octopus with high parasitic infection; on the contrary, peptidoglycan recognition patterns (PGRP), C1q binding protein and oxidative activity expressions, were downregulated (Castellanos-Martinez and Gestal, 2011). Octopus with high coccidian load shown an upregulation in cytoskeletal proteins as actin, filamin, and fascin due to an increases of phagocitotic activity (Castellanos-Martínez et al., 2014b), in particular fascin, known to directly contributing to the regulation of immune response (Feng and Walsh, 2004). All these findings, at the molecular levels, could be further used in identifying molecular markers for octopus's resistance to coccidiosis; and when all this is combined with transcriptomic and proteomic results, a better understanding of the immune system and its response to pathogens could be achieved.

First results coming from epigenetic approach revealed that the genome of $O$. vulgaris is widely methylated with no differences between the sex but with some differences in the mantle of specimens at different stage of maturity, probably due to the complex hormonal machinery that regulates the reproduction (Díaz-Freije et al., 2014; Di Cosmo and Polese, 2014; Polese et al., 2015). Interestingly but not surprising, the methylation pattern found in octopus paralarvae were higher than those observed in the adult animals (DíazFreije et al., 2014). O. vulgaris has a short life span, and octopus at the paralarval stage are considered very susceptible to environmental conditions as in, food availability and presence of predators. These environmental conditions might affect the gene transcription through epigenetic mechanisms influencing development of the immune system to face and improve survival and health. All these facts reveal that immune response in cephalopods could be more complex and evolved than expected (Figure 1; Castellanos-Martínez et al., 2014a).

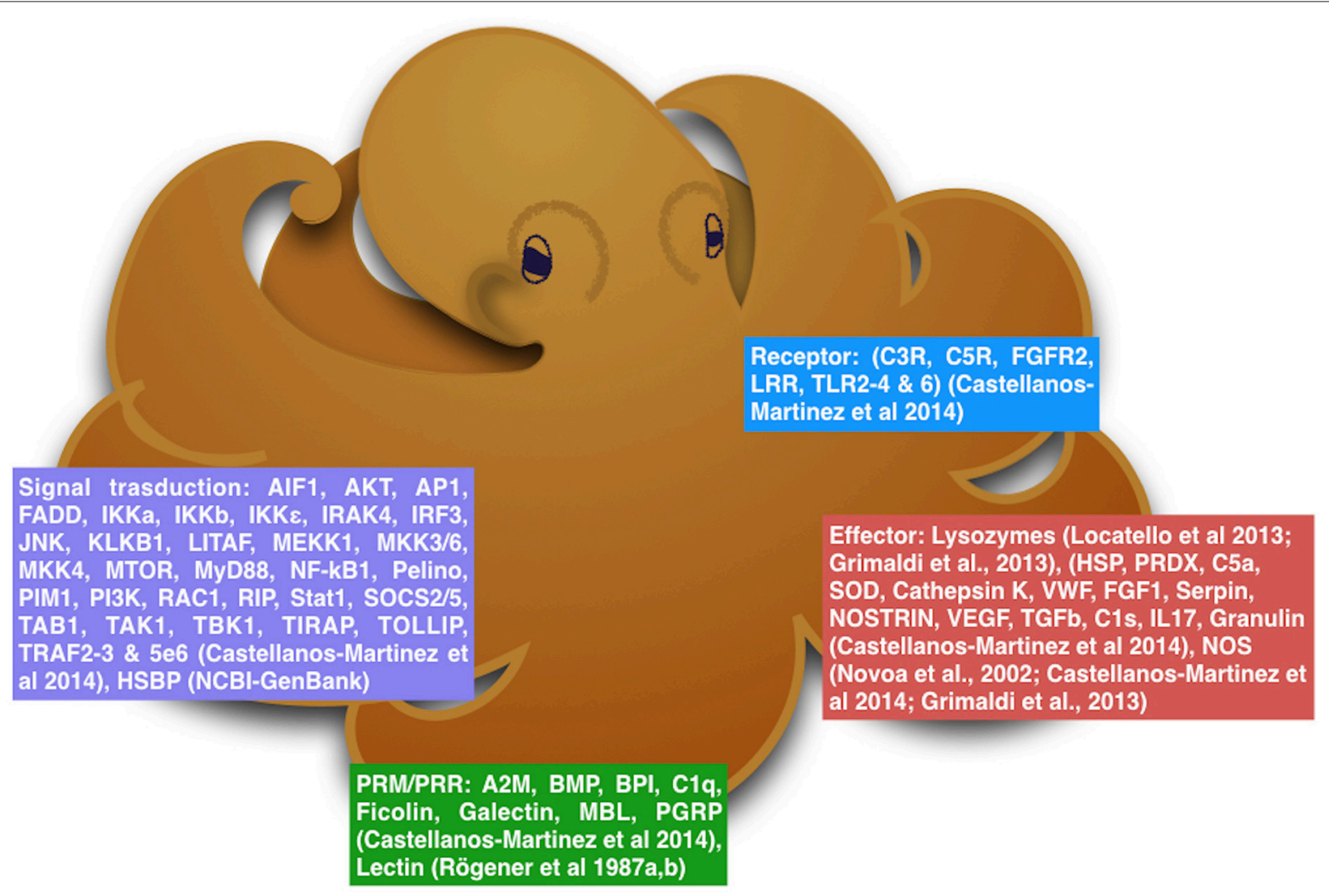

FIGURE 1 | The diagram reassumes the molecular mechanisms that octopus can use to protects itself from environmental stressors. 


\section{HOW NEUROENDOCRINE-IMMUNE SYSTEMS COOPERATE IN RESPONSE TO STRESS STIMULI IN O.vulgaris?}

Throughout evolution, organisms always had a need to detect and respond to environmental conditions and challenges. Among animals, diversification in sensory and signaling systems has resulted in beneficial adaptations as well as variable sensitivity to different stresses. While there is a substantial evidence about the role played by the neuroendocrine crosstalk to regulate the fundamental physiological balancing between energy storage and reproduction in O. vulgaris (Di Cosmo and Polese, 2014; Polese et al., 2015), as well as many information regarding the immune system and defense (Troncone et al., 2014; Gestal et al., 2015), it is important to indicate that to our knowledge, and despite the fact that cephalopods possess a number of specializations as in, signaling molecules, appropriate receptors placed on specific cells, and mechanisms to transmit peripheral immune signals across the blood brain barrier, there are just a few data describing the interaction between the neuroendocrine and immune systems to respond to environmental challenges (Malham et al., 2002; Larson and Anderson, 2010).
However, the work made by Larson and Anderson (2010) on fecal corticosterone level in captive Enteroctopus dofleini represents a useful tool to evaluate the connection between the neuroendocrine and immune system. They demonstrate by immunoassay that fecal corticosterone levels increased after administrating three stresses, including the adrenal gland stimulator ACTH. In vertebrates this hormone, as well as glucocorticoids, are secreted by pituitary or adrenal gland in response to stressful events and are considered stress hormone. In the last 20 years, the presence and the role played by the axe nervous system/subpedunculate area/optic gland/gonad resembling the vertebrate HPG axe has been widely demonstrated in O. vulgaris. The presence and function exerted by sex-steroid, neuro-steroids and their receptors shaping the adaptive responses strongly supports the release of corticosterone (Larson and Anderson, 2010; De Lisa et al., 2012; Polese et al., 2015). Octopuses exposed to different stressful stimuli, that negatively affect growth, reproduction, metabolism, osmoregulation, and immune ability, usually release corticoid stress hormones; the corticosterone that could be released through the nervous system/sub-pedunculate area/optic gland represents a link between neuroendocrine and immune systems

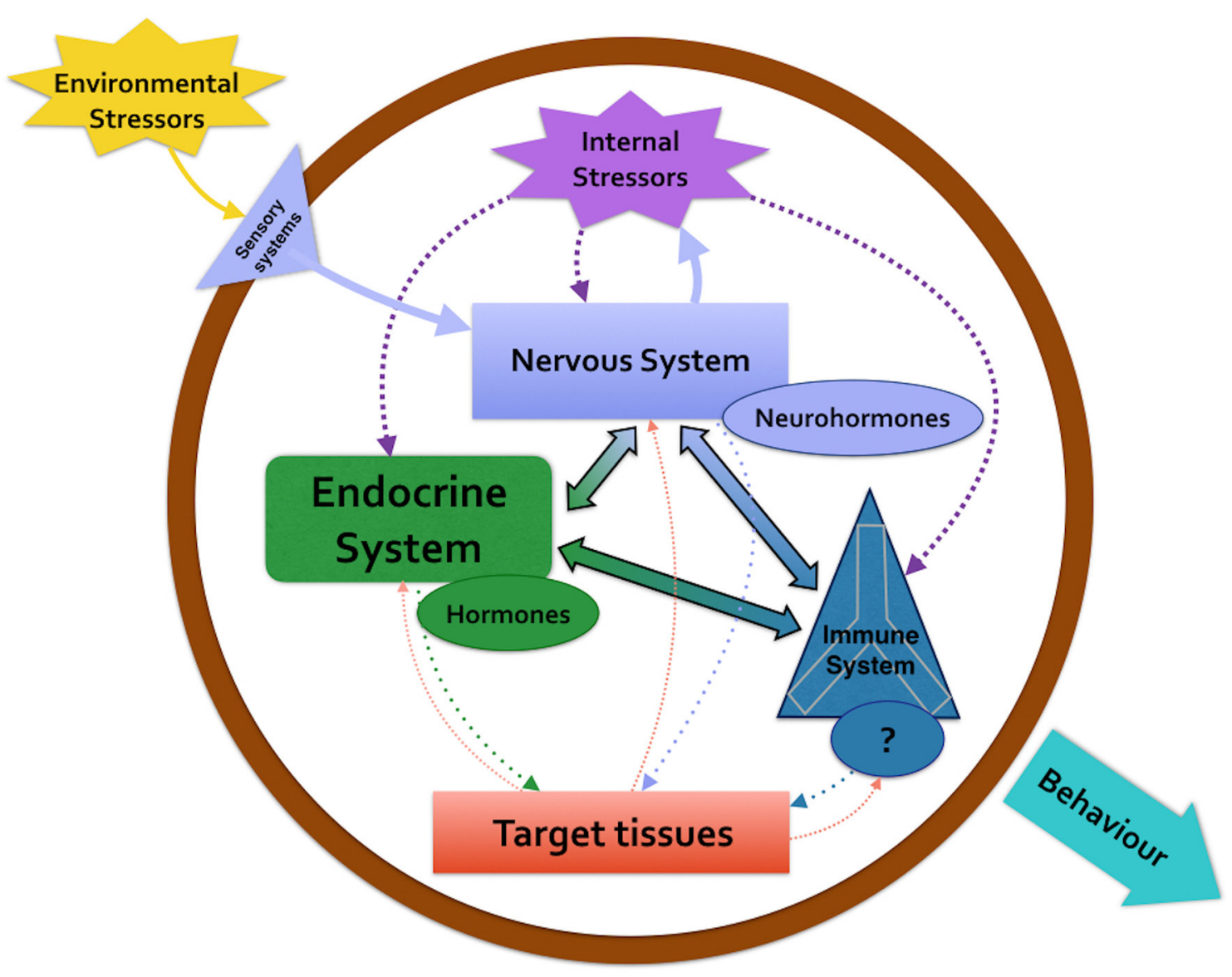

FIGURE 2 | The diagram describes the crosstalk among nervous system, endocrine system and immune system in response to an environmental stressor in Octopus vulgaris. 
in response to stresses (Figure 2; Di Cosmo and Di Cristo, 1998; Di Cosmo et al., 2001, 2002; De Lisa et al., 2012; Di Cosmo and Polese, 2013; Polese et al., 2015).

In general, and due to the complexity of animal responses to environmental and chemical factors needs more attentions form workers in this field, to evaluate how the neuroendocrine and immune systems interact each other to better understand the animal heath at individual and population levels.

\section{REFERENCES}

Adamo, S. A. (2008a). Norepinephrine and octopamine: linking stress and immune function across phyla. Invertebr. Surviv. J. 5, 12-19.

Adamo, S. A. (2008b). "Bidirectional connections between the immune system and the nervous system in insects," in Insect Immunology, ed N. E. Beckage (San Diego, CA: Academic Press), 129-149.

Adamo, S. A. (2010). Why should an immune response activate the stress response? Insights from the insects (the cricket Gryllus texensis). Brain Behav. Immun. 24, 194-200. doi: 10.1016/j.bbi.2009.08.003

Adamo, S. A. (2012). The effects of the stress response on immune function in invertebrates: an evolutionary perspective on an ancient connection. Horm. Behav. 62, 324-330. doi: 10.1016/j.yhbeh.2012.02.012

Albertin, C. B., Simakov, O., Mitros, T., Wang, Z. Y., Pungor, J. R., EdsingerGonzales, E., et al. (2015). The Octopus genome and the evolution of cephalopod neural and morphological novelties. Nature 524, 220-224. doi: 10.1038 /nature 14668

Alpuche, J., Pereyra, A., Mendoza-Hernández, G., Agundis, C., Rosas, C., and Zenteno, E. (2010). Purification and partial characterization of an agglutinin from Octopus maya serum. Comp. Biochem. Physiol. B Biochem. Mol. Biol. 156, 1-5. doi: 10.1016/j.cbpb.2010.01.006

Beuerlein, K., Löhr, S., Westermann, B., Ruth, P., and Schipp, R. (2002). Components of the cellular defense and detoxification system of the common cuttlefish Sepia officinalis (Mollusca, Cephalopoda). Tissue Cell 34, 390-396. doi: 10.1016/S0040816602000708

Beuerlein, K., Schimmelpfennig, R., Westermann, B., Ruth, P., and Schipp, R. (1998). Cytobiological studies on hemocyanin metabolism in the branchial heart complex of the common cuttlefish Sepia officinalis (Cephalopoda, Dibranchiata). Cell Tissue Res. 292, 587-595. doi: 10.1007/s0044100 51088

Blalock, J. E. (1989). A molecular basis for bidirectional communication between the immune and neuroendocrine systems. Physiol. Rev. 69, 1-32.

Castellanos-Martínez, S., Arteta, D., Catarino, S., and Gestal C. (2014a). De Novo transcriptome sequencing of the Octopus vulgaris hemocytes using Illumina RNA-Seq. Technology: response to the infection by the gastrointestinal parasite Aggregata octopiana. PLoS ONE 9:107873. doi: 10.1371/journal.pone. 0107873

Castellanos-Martínez, S., Diz, A. P., lvarez-Chaver, P. A., and, Gestal, C. (2014b). Proteomic characterization of the hemolymph of Octopus vulgaris infected by the protozoan parasite Aggregata octopiana. J. Proteomics 13, 151-163. doi: 10.1016/j.jprot.2013.12.008

Castellanos-Martinez, S., and Gestal, C. (2011). Immune response of Octopus vulgaris against the infection by the gastrointestinal parasite Aggregata octopiana. J. Shellfish Res. 30, 997-998.

Castellanos-Martínez, S., and Gestal, C. (2013). Pathogens and immune response of cephalopods, J. Exp. Mar. Biol. Ecol. 447, 14-22. doi: 10.1016/j.jembe.2013.02.007

Castillo, D., Christiansen, R. H., Dalsgaard, I., Madsen, L., and Middelboe, M. (2015). Bacteriophage resistance mechanisms in the fish pathogen Flavobacterium psychrophilum: linking genomic mutations to changes in bacterial virulence factors. Appl. Environ. Microbiol. 81, 1157-1167. doi: 10.1128/AEM.03699-14

Cohen, N., and Kinney, K. S. (2007). "Exploring the phylogenetic history neuralimmune system interactions: an update," in Psychoneuroimmunology, 4th Edn. ed R. Aders (New York, NY: Elsevier), 1-38.

\section{AUTHOR CONTRIBUTIONS}

$\mathrm{AD}$ and GP equally contributed to this mini review.

\section{FUNDING}

This work was supported by grants from the Italian Ministry of University and Research: FFO2014, FFO2015.

Cowden, R. R. (1972). Some cytological and cytochemical observations on leukopoietic organs, the "white bodies" of Octopus vulgaris. J. Invertebr. Pathol. 19, 113-119. doi: 10.1016/0022-2011(72)90196-6

da Silva, P. M., Comesana, P., Fuentes, J., and Villalba, A. (2008). Variability of haemocyte and haemolymph parameters in European flat oyster Ostrea edulis families obtained from brood stocks of different geographical origins and relation with infection by the protozoan Bonamia ostreae. Fish Shellfish Immunol. 24, 551-563. doi: 10.1016/j.fsi.2007.11.003

De Lisa, E., Paolucci, M., and Di Cosmo, A. (2012). Conservative nature of oestradiol signalling pathways in the brain lobes of Octopus vulgaris involved in reproduction, learning and motor coordination. J. Neuroendocrinol. 24, 275-284. doi: 10.1111/j.1365-2826.2011.02240.x

De Lisa, E., Salzano, A. M., Moccia, F., Scaloni, A., and Di Cosmo, A. (2013). Sperm-attractant peptide influences the spermatozoa swimming behavior in internal fertilization in Octopus vulgaris. J. Exp. Biol. 216, 2229-2237. doi: 10.1242/jeb.081885

Demas, G. E., Adamo, S. A., and French, S. S. (2010). Neuroendocrine-immune crosstalk in vertebrates and invertebrates: implications for host defence. Funct. Ecol. 25, 29-39. doi: 10.1111/j.1365-2435.2010.01738.x

Díaz-Freije, E., Gestal, C., Castellanos-Martínez, S., and Moran, P. (2014). The role of DNAmethylation on Octopus vulgaris development and their perspectives. Front. Physiol. 5:62. doi: 10.3389/fphys.2014.00062

Di Cosmo, A., and Di Cristo, C. (1998). Neuropeptidergic control of the optic gland of Octopus vulgaris: FMRF-amide and GnRH immunoreactivity. J. Comp. Neurol. 398, 1-12. doi: 10.1002/(SICI)1096-9861(19980817)398:1<1::AID$\mathrm{CNE} 1>3.0 . \mathrm{CO} ; 2-5$

Di Cosmo, A., Di Cristo, C., and Paolucci, M. (2001). Sex steroid hormone fluctuations and morphological changes of the reproductive system of the female of Octopus vulgaris throughout the annual cycle. J. Exp. Zool. 289, 33-47. doi: 10.1002/1097-010X(20010101/31)289:13.0.CO;2-A

Di Cosmo, A., Di Cristo, C., and Paolucci, M. (2002). A estradiol-17beta receptor in the reproductive system of the female of Octopus vulgaris: characterization and immunolocalization. Mol. Reprod. Dev. 61, 367-375. doi: 10.1002/mrd. 10014

Di Cosmo, A., and Polese, G. (2013). "Molluscan bioactive peptide," in Handbook of Biologically Active Peptides, ed A. J. Kastin (Amsterdam: Academic Press is an Imprint of Elsevier), 276-286.

Di Cosmo, A., and Polese, G. (2014). "Cephalopods meet Neuroecology: the role of chemoreception in Octopus vulgaris reproductive behaviour," in Neuroecology and Neuroethology in Molluscs - The Interface between Behaviour and Environment, eds A. Di Cosmo and W. Winlow (New York, NY: NOVA Science Publisher), 117-132.

Doubleday, Z. A., Prowse, T. A. A., Arkhipkin, A., Pierce, G. J., Semmens, J., Steer, M., et al. (2016). Global proliferation of cephalopods. Curr. Biol. 26, R406-R407. doi: 10.1016/j.cub.2016.04.002

Elenkov, I. J., Wilder, R. L., Chrousos, G. P., and Vizi, E. S. (2000). The sympathetic nerve - an integrative interface between two supersystems: the brain and the immune system. Pharmacol. Rev. 52, 595-638.

Ellis, R. P., Parry, H., Spicer, J. I., Hutchinson, T. H., Pipe, R. K., and Widdicombe, S. (2011). Immunological function in marine invertebrates: responses to environmental perturbation. Fish Shellfish Immunol. 30, 1209-1222. doi: 10.1016/j.fsi.2011.03.017

Feng, Y., and Walsh, C. A. (2004). The many faces of filamin: a versatile molecular scaffold for cell motility and signaling. Nat. Cell Biol. 6, 1034-1038. doi: $10.1038 /$ ncb1104-1034 
Ford, L. A. (1992). Host defense mechanisms of cephalopods. Annu. Rev. Fish Dis. 2, 25-41. doi: 10.1016/0959-8030(92)90054-2

Gestal, C., and Castellanos-Martínez, S. (2015). Understanding the cephalopod immune system based on functional and molecular evidence. Fish Shellfish Immunol. 46, 120-130. doi: 10.1016/j.fsi.2015.05.005

Gestal, C., Guerra, A., and Pascual, S. (2007). Aggregata octopiana (Protista: Apicomplexa): a dangerous pathogen during commercial Octopus vulgaris ongrowing. ICES J. Mar. Sci. 64, 1743-1748. doi: 10.1093/icesjms/fsm154

Gestal, C., Prado-Alvarez, M., García, P., Iglesias, J., Otero, J. J., and Almansa, E. (2015). "Transcriptome of the first life stages of the common octopus (Octopus vulgaris), Study of epigenetic regulation and biomarkers of welfare and health on the OCTOWELF project," in ISDCI Congress (Murcia).

Grimaldi, A. M., Belcari, P., Pagano, E., Cacialli, F., and Locatello, L. (2013). Immune responses of Octopus vulgaris (Mollusca: Cephalopoda) exposed to titanium dioxide nanoparticles. J. Exp. Mar. Biol. Ecol. 447, 123-127. doi: 10.1016/j.jembe.2013.02.018

Humphries, J. E., and Yoshino, T. P. (2003). Cellular receptors and signal transduction in molluscan hemocytes: connections with the innate immune system of vertebrates. Integ. Comp. Biol. 43, 305-312. doi: 10.1093/icb/43.2.305

Jereb, P., and Roper, C. F. E. (2005). Cephalopods of the World: an annotated and illustrated catalogue of Cephalopod Species known to date, Vol. 1, Chambered Nautiluses and Sepioids (Nautilidae, Sepiidae, Sepiolidae, Sepiadariidae, Idiosepiidae and Spirulidae). FAO Species Catalogue for Fisheries Purposes, No. 4, Vol. 1. Rome: FAO.

Kassahn, K. S., Crozier,. R. H., Pörtner, H. O., and Caley, M. J. (2009). Animal performance and stress: responses and tolerance limits at different levels of biological organisation. Biol. Rev. Camb. Philos. Soc. 84, 277-292. doi: 10.1111/j.1469-185X.2008.00073.x

Ketata, I., Denier, X., Hamza-Chaffai, A., and Minier, C. (2008). Endocrine-related reproductive effects in molluscs. Comp. Biochem. Physiol. C 147, 261-270. doi: $10.1016 /$ j.cbpc.2007.11.007

LaFont, R. (2000). The endocrinology of invertebrates. Ecotoxicology 9, 41-57. doi: 10.1023/A:1008912127592

Larson, S., and Anderson, R. C. (2010). Fecal hormones measured within giant pacific octopuses Enteroctopus dofleini. J. Aquat. Anim. Health 22, 152-157. doi: 10.1577/H09-027.1

Locatello, L., Fiorito, G., Finos, L., and Rasotto, M. B. (2013). Behavioural and immunological responses to an immune challenge in Octopus vulgaris. Physiol. Behav. 122, 93-99. doi: 10.1016/j.physbeh.2013.08.029

Malham, S. K., Lacoste, A., Gélébart, F., Cueff, A., and Poulet S. A. (2002). A first insight into stress-induced neuroendocrine and immune changes in the octopus Eledone cirrhosa. Aquat. Living Resour. 15, 187-192. doi: 10.1016/ S0990-7440(02)01173-7

Nagle, G. T., Painter, S. D., and Blankenship, J. E. (1989). Post-translational processing in model neuroendocrine systems: precursors and products that coordinate reproductive activity in Aplysia and Lymnaea. J. Neurosci. Res. 23, 359-370. doi: 10.1002/jnr.490230402

Novoa, B., Tafalla, C., Guerra, A., and Figueras, A. (2002). Cellular Immunological parameters of the Octopus, Octopus vulgaris. J. Shellfish Res. 21, 243-248.

Ottaviani, E., and Franceschi, C. (1996). The neuroimmunology of stress from invertebrates to man. Progr. Neurobiol. 48, 421-440. doi: 10.1016/03010082(95)00049-6

Ottaviani, E., Malagoli, D., Capri, M., and Franceschi, C. (2008). Ecoimmunology: is there any room for the neuroendocrine system? BioEssays 30, 868-874. doi: 10.1002/bies.20801

Pascual, S., and Guerra, A. (2001). Vexing question on fisheries research: the study of cephalopods and their parasites. Iberus 19, 87-95.

Pascual, S., Rocha, F., and Guerra, A. (2006). Gross lesions in the Hubb octopus Octopus hubbsorum. Mar. Biol. Res. 2, 420-423. doi: 10.1080/174510006010 50451
Pazos, A. J., and Mathieu, M. (1999). Effects of five natural gonadotropinreleasing hormones on cell suspensions of marine bivalve gonad: stimulation of gonial DNA synthesis. Gen. Comp. Endocrinol. 113, 112-120. doi: 10.1006/gcen.1998.7186

Polese, G., Bertapelle, C., and Di Cosmo, A. (2015). Role of olfaction in Octopus vulgaris reproduction. Gen. Comp. Endocrinol. 210, 55-62. doi: 10.1016/j.ygcen.2014.10.006

Rauta, P. R., Samanta, M., Dash, H. R., Nayak, B., and Das, S. (2013). Tolllike receptors (TLRs) in aquatic animals: signaling pathways, expressions and immune responses. Immunol. Lett. 158, 14-24. doi: 10.1016/j.imlet.2013.11.013

Rodríguez-Domínguez, H., Soto-Búa, M., Iglesias-Blanco, R., CrespoGonzalez, C., Arias-Fernandez, C., and García-Estevez, J. (2006). Preliminarystudyonthe phagocytic ability of Octopus vulgaris Cuvier, 1797 (Mollusca: Cephalopoda) haemocytes in vitro. Aquaculture 254, 563-570. doi: 10.1016/j.aquaculture.2005.10.005

Rögener, W., Renwrantz, L., and Uhlenbruck, G. (1987a). Isolation and characterization of a lectin from the hemolymph of the cephalopod Octopus vulgaris (Lam.) inhibited by alpha-D-lactose and $\mathrm{N}$-acetyl-lactosamine. Dev. Comp. Immunol. 9, 605-616. doi: 10.1016/0145-305X(85)90026-6

Rögener, W., Renwrantz, L., and Uhlenbruck, G. (1987b). Analysis of Octopus vulgaris hemolymph containing a glycoprotein with blood group A-like properties. Comp. Biochem. Phys. B Comp. Biochem. 86, 347-351. doi: 10.1016/0305-0491(87)90304-X

Schipp, R. (1987). General morphological and functional characteristics of the cephalopod circulatory system. An introduction. Cell. Mol. Life Sci. 43, 474-477. doi: 10.1007/BF02143574

Smit, A. B., Vreugdenhil, E., Ebberink, R. H., Geraerts, W. P., Klootwijk, J., and Joosse, J. (1988). Growth-controlling molluscan neurons produce the precursor of an insulin-related peptide. Nature 331, 535-538. doi: 10.1038/331535a0

Smith, L. C., Chang, L., Britten, R. J., and Davidson, E. H. (1996). Sea urchin genes expressed in activated coelomocytes are identified by expressed sequence tags. Complement homologues and other putative immune response genes suggest immune system homology within the deuterostomes. J. Immunol. 156, $593-602$.

Tada, T. (1997). The immune system as a supersystem. Annu. Rev. Immunol. 15, 1-13. doi: 10.1146/annurev.immunol.15.1.1

Troncone, L., De Lisa, E., Bertapelle, C., Porcellini, A., Laccetti, P., Polese, G., et al. (2014). Morphofunctional characterization and antibacterial activity of haemocytes from Octopus vulgaris. J. Nat. Hist. 49, 1457-1475. doi: 10.1080/00222933.2013.826830

Vaz-Pires, P., Seixas, P., and Barbosa, A. (2004). Aquaculture potential of the common octopus (Octopus vulgaris Cuvier, 1797): a review. Aquaculture 238, 221-238. doi: 10.1016/j.aquaculture.2004.05.018

Webster, J. I., Tonelli, L., and Sternberg, E. M. (2002). Neuroendocrine regulation of immunity. Annu. Rev. Immunol. 20, 125-163. doi: 10.1146/annurev.immunol.20.082401.104914

Wells, M. J., and Smith, P. J. S. (1987). The performance of the Octopus circulatory system: a triumph of engineering over design. Experientia 43, 487-499. doi: 10.1007/BF02143577

Conflict of Interest Statement: The authors declare that the research was conducted in the absence of any commercial or financial relationships that could be construed as a potential conflict of interest.

Copyright $\odot 2016$ Di Cosmo and Polese. This is an open-access article distributed under the terms of the Creative Commons Attribution License (CC BY). The use, distribution or reproduction in other forums is permitted, provided the original author(s) or licensor are credited and that the original publication in this journal is cited, in accordance with accepted academic practice. No use, distribution or reproduction is permitted which does not comply with these terms. 